\title{
\#ECAPACITAR - A PATH TOWARDS AN INNOVATIVE AND TAILORED ELEARNING SOLUTION IN A HEI
}

\author{
A. Loureiro', D. Rocha' ${ }^{2}$ P. Santos Silva ${ }^{2}$ \\ ${ }^{1}$ Instituto Politécnico de Santarém; LE@D; CIAC (PORTUGAL) \\ ${ }^{2}$ Instituto Politécnico de Santarém (PORTUGAL)
}

\begin{abstract}
The paper showcases the methodology used to design a project in a HEI in the field of distance education. \#eCapacitar is a capacity building project for digital inclusion in IPSantarém's core areas. The project is ongoing and it has 3 main axes that will develop and implement the following infrastructure: a CRM platform, an eLearning solution and a Digital Knowledge Database. The main focus of the paper will be the aspects related with an innovative and tailored eLearning solution. Although the institution is already carrying out some training offers based on eLearning, it's lacking a more sustainable, grounded and systematic infrastructure. Only with high quality standards HEl can be competitive and face the upcoming challenges, able to respond to the needs of a 21 st century citizen. The training offer must prepare students in order to develop competencies such as the transformative, digital, soft and emotional ones. We have to think not only about the technology behind it but also cherish the conceptual learning model that supports the distance education solution, whose reasoning and design will result from the phase of planning currently in development.
\end{abstract}

Keywords: \#eCapacitar, e-learning, LMS, distance education, open science, capacity building.

\section{INTRODUCTION}

Open Science has been growing in recent years at national and international level, under the premise that knowledge belongs to all and for all. It represents a new approach to the scientific process based on cooperative work and new ways of disseminating knowledge, using digital technologies and collaborative tools [1]. Scientific research should thus be shared and reused, with Open Access, Open Data, Open Research and Innovation, Open Science Networks, and Citizen Science identified as supporting pillars [2]. These pillars are consolidated from the institutional point of view, through Science, Development \& Innovation Policies and Strategies, Legislation, Open Educational Resources (OER) and Open Science Initiatives, so that societies are developed from the social, economic and cultural point of view in favour of the quality of life of all citizens. Making research results more accessible to all social actors contributes to a better and more efficient science and innovation in the public and private sectors. On this basis, the IPSantarém, as a higher education institution (HEI) whose mission is the production and dissemination of knowledge, creation, transmission and dissemination of knowledge of a professional nature, culture, science, technology, arts, research; considers strategic the implementation of an innovative eLearning solution adapted to the needs of contemporary society. Therefore, the \#eCapacitar project was outlined, which aims to stimulate and increase the adoption of distance learning courses through the implementation of an infrastructure capable of applying synchronous and asynchronous communication means that allow the fulfilment of a whole framework of distance education, training and capacity building, within the process of modernization of the services to be provided to the communities served by IPSantarém. Trying, in this way, to increase its potential for attracting students, providing services and transferring knowledge, in its business areas. In this paper we will present the strategy and the methodology adopted towards the implementation of the \#eCapacitar project, in the specific axe of distance education and the proposed innovative and tailored eLearning solution.

\section{ELEARNING IN HEI}

Although the concept of eLearning has been widely discussed over the years and despite the fact we can find in the literature many definitions, Sangrà, Vlachopoulos, and Cabrera [3] undertaken a study "based on the participation of experts around the world, (...) to agree on a definition of e-learning" (pp. 145). This definition intends to be a more inclusive one and it states as: "E-learning is an approach to teaching and learning, representing all or part of the educational model applied, that is based on the use of electronic media and devices as tools for improving access to training, communication and interaction 
and that facilitates the adoption of new ways of understanding and developing learning" (pp. 152). In the \#eCapacitar project we took this definition in consideration, because we agree it's a more inclusive and equitable one and it's in line with The Global Education 2030 Agenda principles, meeting the Sustainable Development Goal 4 (SDG4): "Ensure inclusivity and quality education and promote lifelong learning opportunities for all" [4].

Digital information and communication technologies (ICT) and online and virtual platforms play a key role in contemporary society. This role, during the CoViD19 pandemic, assumed special relevance namely in Distance Learning, Emergency Remote Learning and Online Education. Higher Education Institutions (HEI) have the responsibility, regardless of the contexts, to provide quality and inclusive education. It was up to the institutions and teachers to develop digital inclusion measures and processes, which allowed them to continue the teaching and learning process, transforming challenges into opportunities. Inclusive education is a challenge for society, assuming particular relevance during the CoViD-19 pandemic. Students from vulnerable backgrounds were particularly affected, including children and young people from low-income and single-parent families, immigrants, refugees, ethnic minorities and indigenous backgrounds and those with special educational needs. These students were deprived of physical learning opportunities, the social and emotional support available in schools and extra services such as school meals. Educational processes around the world have had to be adapted to containment, and Emergency Remote Learning has further accentuated the technological and digital barriers affecting the most disadvantaged families and the most vulnerable and least digitally skilled students [5]. In reality, we cannot forget that, on the one hand, there are many families with a high level of digital illiteracy, and on the other hand, there may be no (or insufficient) access to computer equipment and the Internet at home. In fact, many institutions "had plans to make greater use of technology in teaching, but the outbreak of Covid-19 has meant that changes intended to occur over months or years had to be implemented in a few days" [6]. The teachers, at a distance and in each extended or virtual classroom, made every effort to maintain the quality of teaching, reinventing strategies and defining new dynamics, adapting to the needs of the students, the contingencies, the constraints and the technological potentialities, adapting, little by little, to the new normal supported and mediated by digital technologies. In the extended or virtual classrooms, aspects such as the possibility of collaboration, communication, sharing and socialization are essential, so the ability to socialize is assumed as a crucial factor for collaborative learning and knowledge construction [7]. In situations where students have or feel difficulties in accessing the extended or virtual classroom, whether due to technical or economic difficulties or illiteracy, it may lead them to feel excluded and to social isolation, accentuating inequalities.

Online Education, through eLearning solutions grounded in digital and virtual platforms, plays an important role in the future of education. $\mathrm{HEI}$ have to define and provide quality training programs bearing in mind the idea that any person around the world is a potential student (learner). The OECD Future of Education and Skills 2030 "aims to help education systems determine the knowledge, skills, attitudes and values students need to thrive in and shape their future" [8]. In order to reach this outcome and to prepare citizens for the 21st century, HEl must provide training programs to develop transformative competencies amongst students. These skills, along with the digital, the emotional and the soft skills, allow students to "contribute to our world and shape a better future: creating new value, reconciling tensions and dilemmas, and taking responsibility" [8]. Although IPSantarém already has a participation in the Distance Education ecosystem, both internationally and nationally, the evidence of this participation is limited to MOOCs, short training courses and curricular units integrated in some formal courses. A structured, organized and institutionalized training offer, in the distance teaching and learning modality, has become one of the strategic axes of institutional policy, as a way of fulfilling its mission as a HEl. With this in mind, the \#eCapacitar project aims to meet Goal 2 of the Contract for the Legislature with Higher Education for 2020 - 2023, which provides for the expansion of adult participation in higher education.

The 2030 Agenda for Sustainable Development [9] has become a structuring and cross-cutting document to address the needs of the population in all societies, emphasizing that "no one is left behind". Addressing the three dimensions of sustainable development goals (SDG): social, economic and environmental, as well as important issues related to peace, justice and more effective and efficient institutions, makes the Quality of Education (SDG4) as one of the SDG, imperative in the \#eCapacitar project, specifically in the thematic axis of eLearning. Defined by the United Nations, accepted by member states and to be Implemented by the structures qualified and identified for that purpose - in this case, a polytechnic higher education institution - this is the central focus of this axis. Inclusion, innovation and capacity building in the IPSantarém business area, are translated into the goals defined in the SDG4 - Quality of Education that intends to "Ensure inclusive and equitable quality education and promote lifelong learning opportunities for all". The need to include a cross-cutting link to SDG17 - Partnership 
for Goals in this project is also highlighted. We cherish and promote ways to "Strengthen the means of implementation and revitalize the global partnership for sustainable development". In the overview of \#eCapacitar is a common element, the partnerships internal and external to the institution - stakeholders - as an emerging context for the success and achievement of the objectives of the same, without which the ecosystem of eLearning in IPSantarém would not be complete. In this SDG17, important aspects stand out, especially for the implementation and sustainability of the project over time. Namely, the issues of Technology, Capacity Building and Systemic Aspects that facilitate the coherence of institutional policies, partnerships and the existence of shared data for monitoring the implementation of the SDGs.

\section{3 \#ECAPACITAR: PROJECT OVERVIEW}

The project "\#eCapacitar - capacity building for digital inclusion in IPSantarém's business areas" (POCI05-5762-FSE-000254 (2020-2023) publicly funded through the SAMA program - Agency for Administrative Modernization), aims to modernize the HEI with a set of means and technological resources necessary to support the different areas of the training offer, research and transfer of knowledge and technology. It will make it possible to improve the quality of the services provided, reinforcing access to digital for the entire IPSantarém educational community. Although the proposal was submitted for public funding before the pandemic arose, the constraints felt due to the Covid19 confirmed and reaffirmed the importance of modernizing IPSantarém in this area as well as the training needs of its employees became more evident. It should be noted that the institution has preferably been an on-site teaching institution, although it has an important and innovative component in the field of technologies and training provision in this area. However, this happens particularly in one of its five schools and, consequently, we find different realities and stages of development and knowledge when considering the IPSantarém. Providing an overview of the Project, its design articulates three major axes of intervention, namely:

- CRM Platform - allows the digital transformation of systems and forms of information and communication through a clear commitment to simplifying processes and facilitating access to a wide range of services, digital technologies and data collection instruments considering the profile of each user as well as the various stakeholders. This platform has an impact: i) In the relationship with support services, including all communication and information processes related to academic management, service times, process and document management, financial and asset management, integrated communication, attendance management, event registration management, e-mail access, schedule management, creation and launch forms, cafeteria management, schedule exchanges, submission management, impression management, scholarship management, reporting of statistical data, creation identification cards, wireless network access, data storage, file sending and sharing, curriculum management, among others; ii) In the Academic Scope, it contributes to reformulating procedures, namely in the access to the bibliographic fund, the collection, treatment and storage of data, in the access to school timetables, among others; iii) In the field of external relations with target audiences, it has an impact at the level of processes related to diverse requirements and requests and the respective flow of information, external communication supports, dissemination of information regarding the training offer of the five Schools, access to job offers, submission of proposals to scientific and technical events and publications, analysis and visualization of public data from the IPSantarém community.

- eLearning Platform - aims to stimulate and increase the adoption of distance learning courses through the implementation of a reference infrastructure allowing the development of synchronous and asynchronous communication and the fulfilment of a whole framework of nonpresence education, training and capacity building, within the process of modernization of the services to be provided to the communities served by IPSantarém. It will have an impact: i) In the increase of its potential for attracting students, providing services and transferring knowledge; ii) In the development of a training program for all those involved in the process, teachers and nonteachers, in order to ensure the quality of the training offer and associated services, which means involving the entire educational community in the process of change underlying the implementation of the project; iii) Standardizing the graphic model for the presentation of academic content (conceiving, designing and developing templates for different types of educational resources and scientific areas, as well as evaluation methodologies and tools); iv) Transferring academic information and content to a format appropriate to the distance education 
modality; v) In the definition and implementation of an internal pedagogical-scientific model of distance education.

- Digital Knowledge Database - to develop in open access a "Knowledge Database" system that privileges the analysis and aggregation of large volumes of data, combining different sources of information. It will have an impact: i) In the compilation, consolidation, organization, analysis, monitoring and evaluation of activities to be developed, in order to preserve and make accessible the collective memory of IPSantarém; ii) In the preservation, availability and access to the content produced at IPSantarém throughout its existence, as well as in its five Higher Schools in which the heritage of scientific, academic and pedagogical knowledge is disseminated in various supports and in diversified devices with little data consolidated and corseted access; iii) The insertion of this heritage of scientific, academic and pedagogical knowledge from IPSantarém, in the Directory of Digital Repositories at national level (project initiated by the Foundation for Science and Technology - Ministry of Science and Higher Education); iv) Integration in a single point of access to the knowledge of the Library Unit and the Scientific Repository of IPSantarém, with internal management although in interoperability with other knowledge bases, namely the Online Knowledge Library - B-on, Arquivo.pt and Scopus.

Oriented towards universal access to information systems, implementation and transformation of digital services, among the main objectives of the project we highlight the simplification of processes and the improvement of the quality of the services provided, reducing costs and execution times, the development of a technological solution of reference for the dissemination of the training offer through non-face-to-face, providing users with an integrated solution to consolidate the teaching-learning processes, the integration of new technologies in the learning processes, optimizing the content production processes; and the development of a training program aimed at the educational community (teaching and non-teaching) of IPSantarém for the effective use of digital tools, pedagogical resources and support infrastructures.

\subsection{Planning and implementation: a work methodology}

Once the project is approved with all its components made explicit, it may seem that much of the planning process is done. In fact, the approval of the project is only the first step to start planning what will give rise to its implementation. As Capucha [10] points out, planning corresponds to the projection of a change, with the forecast of the necessary steps for its realization, identification of the factors that interfere in the process, mobilization of the agents and the necessary means for the projected change to develop as expected. In this sense, there are many things that need to be considered in advance. In order to establish a work methodology, we can make use of several models that apply to the development of projects in general and of projects whose objective is to create a training offer in distance education.

In general, a planning process begins with a diagnostic evaluation. The identification of needs in a sustained manner and through scientifically validated methods and techniques is crucial for a successful transition to the implementation phase. As so, the first thing that must be completed is a Needs Assessment, the planning stage that we are currently in. The Needs Assessment is a process that helps to identify gaps in the current condition or situation, aiming to deepen the perception of current problems that may exist and to help find solutions to such problems or needs; it can vary a lot depending on previous knowledge about situations and their complexity, but it is also informed by the dimensions selected for analysis and the research techniques used [10]. Thus, the time spent collecting data and information will help guide subsequent decisions throughout the implementation process and the instructional design of the training offer. There are some key components of needs assessment that must be taken into consideration. The identification of the audience and stakeholders is one of the first steps to be taken in a needs assessment process, allowing for a deeper understanding and knowledge of all those potentially affected by the project; Another relevant aspect is the development of goals and objectives that allow a clear perception of what is to achieve with the project, both for the design of information-gathering instruments and to the measurement of project objectives themselves - with regard to its feasibility and measurement capacity. Regarding the collection of information, the selection of methods and techniques to be mobilized and their suitability for different target groups should be a concern of the team that conducts the needs assessment. There is a very diverse set of possibilities, however, not all of them are appropriate to the nature of what is sought or to the specifics of the interlocutors selected to provide the information - thus, it is considered that different methodological approaches and the corresponding techniques must be combined; for this purpose, designing and testing the tool(s) to be used, with specific questions addressed to the target audiences, should be a 
priority rather than opting for needs assessment tools that are already available. Information collected through responses that are provided directly should be complemented with a literature review to obtain additional information (primary and secondary data should always be considered). The analysis of the information obtained will allow not only to evaluate and prioritize the needs but also to know the characteristics of the different segments of audiences and, also, to perceive coincidences and inconsistencies with what it is proposed to develop with the project implementation. In other words, it will provide a better understanding of the suitability of the project and will allow adjustments to be made as necessary. Thus, information management must be conducted in such a way that it is possible to return to the data in the subsequent phases of project implementation; the syntheses of information are important tools for the project team but it is equally important to share them with the public and stakeholders, contributing to maintaining their connection with the project and to increase their sense of belonging and involvement in the resulting change process.

Equally important when planning and implementing a project is concerned with managing change. Change Management is a collective term for considering all approaches when planning, preparing, supporting, and helping the audience and stakeholders throughout the transition or change. Any change is always a "hot spot" in an organization. Individual attitudes to change can speed up, slow down, or even prevent the process from moving forward; it is important to bear in mind that the organizational climate and culture influence the change management processes and, consequently, they must be observed and considered as fundamental parts in the management of the process. A fundamental aspect to be considered is related to communication, thought as a key factor in organizational development and not just as an informative procedure for changes and decisions taken; it is an element that facilitates understanding, the incorporation of new concepts and the "socialization of knowledge", that is, the sharing of the organization's goals with all members of the organization tends to make people more collaborative and participatory [11]. As the organization's employees participate in the change process, they are part of a context and have the possibility to participate actively; in the different sectors of an organization, each worker within the scope of his duties is a profound expert on the needs of the service and has the necessary skills to propose solutions and contribute with his knowledge to achieve the objectives - for this he has to be aware of the objectives and goals; which does not mean communicating everything to everyone (internally and externally) without a strategy, it implies also managing the communication processes; identify and analyze stakeholders and their segmentation in accordance with their interests. Following Baptista [11], it is necessary to consider strategic communication in the planning and development objectives of the institution, considering the analysis of the organizational climate and culture, to be considered from the needs assessment phase and to be maintained throughout the process; in fact, the evaluation is not something static that happens only in certain moments (initial and final, for example), it must be an on-going process. Thus, a second fundamental factor arises: participation - which is not limited to the representation of the different categories of employees in Organs and the proper bodies of the academy; it reports on the redefinition of spaces for an integration policy and channels of action / decision. There is a sociocultural dimension in the management of change that refers to the existence of habits, values and beliefs present in the organizational environment and that can condition the management practices of its members, so the analysis of this dimension will allow us to understand the subjective limits of modernization and that manifest themselves in objective behaviours, as a result of the different meanings that individuals give to change [12]. It is essential that Change Management is based on proximity and personal development initiatives so that employees, internal, and external partners, become involved, constituting themselves as agents of change and do not hinder it. Change management deals with people's reactions, which tend to resist change as they get used to doing things in a certain way. For example, teachers who have always taught in face-to-face environments may resist and oppose moving to online teaching and learning environments. Having empathy and understanding resistance in the planning phase can help overcome these barriers, some of which are due to lack of security in the use of technological tools and also in the pedagogical dimension of this teaching-learning modality.

\section{FINAL THOUGHTS}

The phenomenon of public health that we are experiencing today has had the effect that educational institutions around the world have started offering courses and programs online, instead of in face-toface environments, as a way of responding to the situation of crisis. What has been an enormous constraint in education can, however, be turned into an opportunity. With the development and implementation of the \#eCapacitar project, the IPSantarém will have a new organizational and learning model of operation with innovative and efficient features with regard to contact and interaction with stakeholders. It is also expected that, based on the results obtained, this model can be mirrored with 
other HEI in Portugal and abroad. Thus, the above-mentioned project will contribute decisively to enhance the competitive advantages of the Institution with the academic environment and partner entities, not only at a local and regional levels, but also at a national and international one.

Distance education can ensure and facilitate inclusive and equitable quality education and promote lifelong learning in order to tackle societal challenges, as stated in the Education 2030 Framework for Action. Plus, eLearning solutions allow the implementation of more flexible and open pathways, giving students the chance to control their learning in terms not only of time and space but also in terms of curriculum choices. An innovative and flexible training offer allows the take-up, validation and recognition of short learning courses leading to micro-credentials and the implementation of transdisciplinary approaches and innovative pedagogies such as inverted learning, collaborative online international learning and research-based learning. The \#eCapacitar project is a step towards a competitive, efficient, sustainable and innovative Higher Education Institution.

\section{ACKNOWLEDGEMENTS}

Sisterna de Apoio à Modernização e Capacitação da Administração Pública (SAMA 2020). Aprovação da candidatura $n^{\circ}$ POCl-05-5762-FSE-000254, pela Autoridade de Gestão do POOI.

\section{REFERENCES}

[1] EC - European Commission (2016). Open innovation, Open Science, open to the world. A vision for Europe. Retrieved from: https://publications.europa.eu/en/publication-detail//publication/3213b335-1cbc-11e6-ba9a-01aa75ed71a1

[2] MCTES - Ministério da Ciência, Tecnologia e Ensino Superior (2016). Ciência Aberta. Retrieved from: https://www.ciencia-aberta.pt/

[3] Sangrà, A.; Vlachopoulos, D.; Cabrera, N. (2012). Building an Inclusive Definition of E-Learning: An Approach to the Conceptual Framework. IRRODL, Vol 13, N. 2 (pp. 145-159). https://files.eric.ed.gov/fulltext/EJ983277.pdf

[4] UN General Assembly, Transforming our world : the 2030 Agenda for Sustainable Development, 21 October 2015, A/RES/70/1, Retrieved from: https://www.refworld.org/docid/57b6e3e44.html

[5] Fleming, N. (27 março 2020). New Strategies in Special Education as Kids Learn From Home. Edutopia. Retrieved from: https://www.edutopia.org/article/new-strategies-specialeducation-kidslearn-home

[6] Daniel, S. J. (2020). Education and the Covid-19 pandemic. Prospects 49, (pp. 91-96). Retrieved from: https://doi.org/10.1007/s11125-020-09464-3.

[7] Loureiro, A. \& Bettencourt, T. (2014). The Use of Virtual Environments as an Extended Classroom - A Case Study with Adult Learners in Tertiary Education. Procedia Technology, Volume 13, 2014 (pp. 97-106). Retrieved from: https://doi.org/10.1016/j.protcy.2014.02.013

[8] OECD (2015). Future of Education and Skills 2030. Retrieved from: https://www.oecd.org/education/2030-project/

[9] Centro Regional de Informação das Nações Unidas (UNRIC) (2021). Objetivos de Desenvolvimento Sustentável: 17 objetivos para transformar o nosso mundo. Retrieved from https://unric.org/pt/objetivos-de-desenvolvimento-sustentavel/

[10] Capucha, L. (2008). Planeamento e Avaliação de Projectos - Guião prático. Lisboa:DirecçãoGeral de Inovação e de Desenvolvimento Curricular. ISBN 978-972-742-285-2. Retrieved from: https://www.dge.mec.pt/sites/default/files/EPIPSE/planeamento_e_avaliacao_de_projectos__guiao_pratico_capucha_2008.pdf

[11] Baptista, R. D. ( 2003). A comunicação empresarial e a gestão da mudança. Biblioteca online das Ciências da Comunicação. Universidade da Beira Interior. pp.1-5. ISSN:1646-3137. Retrieved from: http://www.bocc.ubi.pt/pag/baptista-renato-comunicacao-gestao.pdf

[12] Sampaio, R. \& Laniado, R. (2009). Uma experiência de mudança da gestão universitária: o percurso ambivalente entre proposições e realizações. Revista de Administração Pública (Brasil) Num. 1 Vol.43. 43. 10.1590/S0034-76122009000100008. 